\title{
Pathways of Retinol and Retinoic Acid Metabolism in the Rat
}

\author{
By ANITA B. ROBERTS AND H. F. DeLUCA \\ Department of Biochemistry, University of Wisconsin, Madison, Wis. 53706, U.S.A.
}

(Received 17 June 1966)

\begin{abstract}
1. The metabolism of retinoic acid and retinyl acetate labelled with ${ }^{14} \mathrm{C}$ in various positions was studied after intravenous injection of physiological amounts of these compounds into retinol-deficient rats. 2. Analysis of the resultant radioactivity in the urine, carbon dioxide and faeces led to a postulation of the existence of three major pathways for the metabolism of these two compounds. 3. Evidence is presented that retinoic acid and retinol are metabolized by either the same or at least similar pathways and that retinol becomes oxidized to the carboxyl state before any degradation of the isoprenoid side chain occurs. 4. It is not possible to decide from these data whether retinoic acid is an intermediate in the retinol pathway. 5. Possible sites for the regulation of retinol metabolism are discussed.
\end{abstract}

Since the discovery of retinol early in this century, much fruitful effort has been expended in the elucidation of the physiological effects of retinol deficiency. On the other hand, surprisingly little is understood about the metabolism of the vitamin molecule itself and the molecular events leading to its action in supporting growth. The discovery by Arens \& van Dorp (1946a) (see also Sharman, 1949) of the growth-promoting activity of retinoic acid in retinol-deficient rats opened up the possibility of its involvement in the main pathway of retinol metabolism.

It is known that, though retinol and retinal are readily interconvertible (Wald \& Hubbard, 194849; Zachman \& Olson, 1961 ; Futterman \& Saslaw, 1961 ), the conversion of retinal into retinoic acid is enzymically irreversible in vitro (Dmitrovskii, 1961; Futterman, 1962; Elder \& Topper, 1962; Mahadevan, Murthy \& Ganguly, 1962). This is borne out by repeated failures to detect any retinol in liver even after massive dosing with retinoic acid (Sharman, 1949; Arens \& van Dorp, 1946b; DeMan, Leeuwen \& Roborgh, 1964) and also by the failure of retinoic acid to substitute for retinal in the visual cycle (Dowling \& Wald, 1960). Conversely, most attempts to trap retinoic acid formed as a product of administered retinol or retinal have been unsuccessful (Krishnamurthy, Bieri \& Andrews, 1963; Wright, 1960). But recently it has been shown that large doses of retinal do lead to the production of small amounts of retinoic acid in the tissues (Deshmukh, Malathi \& Ganguly, 1965) and in the bile, where a watersoluble conjugate of retinoic acid is found as well (Dunagin, Zachman \& Olson, 1964). These experiments leave little doubt that the necessary enzymes for the conversion of retinol into retinoic acid are present. However, whether or not retinoic acid is an intermediate in the main pathway of retinol metabolism with a high turnover rate or is on a shunt that can in some manner still lead to a compound with 'retinol activity' remains an open question.

The experiments described in the present paper provide evidence that, regardless of whether retinoic acid is on a shunt or directly participates in the main pathway of retinol metabolism, its degradation follows a pathway common to the degradation of retinol, for the overall metabolism of retinyl acetate and retinoic acid have similar patterns.

\section{MATERIALS AND METHODS}

Radioactive compounds. $\quad\left[6,7-14 \mathrm{C}_{2}\right]$ Retinoic acid, $\left[6,7-14 \mathrm{C}_{2}\right]$ retinyl acetate and $[15-14 \mathrm{C}]$ retinoic acid were gifts from Hoffmann-La Roche and Co. (Basel, Switzerland, and Nutley, N.J., U.S.A.). [14-14C]Retinoic acid was obtained from Tracerlab (Waltham, Mass., U.S.A.) and [15.14C] retinyl acetate was obtained from Nuclear-Chicago Corp. (Des Plaines, Ill., U.S.A.). All compounds were purified by thin-layer chromatography on plain silica gel immediately before each experiment. The chromatograms were developed with $10 \%(\mathrm{v} / \mathrm{v})$ methanol in benzene for retinoic acid and $20 \%(\mathrm{v} / \mathrm{v})$ ether in cyclohexane was used for retinyl acetate. The compounds were eluted with ethanol in the dark under $\mathrm{N}_{2}$, evaporated to dryness under a stream of $\mathrm{N}_{2}$ and redissolved in $0.9 \% \mathrm{NaCl}$ containing $0.1 \%$ of Tween 40 (polyoxyethylene sorbitan monopalmitate; obtained from the Atlas Powder Co., Wilmington, Del., U.S.A.). For the retinoic acid experiments, the concentration was approx. $15 \mu \mathrm{g} . / 0 \cdot 2 \mathrm{ml}$. and the solution was adjusted to $\mathrm{pH8.5}$ with $\mathrm{NaOH}$. For retinyl acetate, the concentration was $2 \mu \mathrm{g} . / 0 \cdot 2 \mathrm{ml}$. and the solution also 
contained approx. $100 \mu \mathrm{g}$. of $\alpha$-tocopherol $/ 0 \cdot 2 \mathrm{ml}$. These concentrations were chosen to approach the minimum dose necessary to support growth (Zile \& DeLuca, 1965). The u.v. spectra of these solutions were read on a Cary model 15 recording spectrophotometer immediately before injection to determine the exact concentrations; specific activity was also determined. All solvents were A.R. grade.

Preparation of animals. Weanling male albino rats (Holtzman Co., Madison, Wis., U.S.A.) weighing 40-50g. were placed on a purified retinol-deficient diet (DeLuca, Manatt, Madsen \& Olson, 1963). In about 4 weeks they reached a plateau in growth rate and were placed on retinoic acid supplements ( $50 \mu \mathrm{g}$./day) until they weighed 225-275g. Rats for the retinyl acetate experiments were first supplemented for 1-2 weeks with 1.5-2 $\mu \mathrm{g}$. of retinol/ day and were used 4 days after the last such supplement.

Administration of retinoic acid or retinyl acetate. The rats were lightly anaesthetized with ether and were given $14.5 \mu \mathrm{g}$. of radioactive retinyl acetate by intrajugular injection. They were placed in glass metabolism cages (Delmar Science Laboratories, Chicago, Ill., U.S.A.) for $48 \mathrm{hr}$., where respiratory $\mathrm{CO}_{2}$, urine and faeces were collected. The rats were then transferred to open metabolism cages for further collection of urine and faeces. Rats received $100 \mu \mathrm{g}$. of non-radioactive retinoic acid (retinoic acid experiments) on the third day of the experiment or $3 \mu \mathrm{g}$. of non-radioactive retinol (retinol experiments) on the fifth day of the experiment.

Radioactivity of respiratory carbon dioxide. The $\mathrm{CO}_{2}$ was removed from the metabolism cage by a stream of $\mathrm{CO}_{2}$-free air flowing at a rate of $500-700 \mathrm{ml}$. $/ \mathrm{min}$. It was trapped in $100 \mathrm{ml}$. portions of ethylene glycol monomethyl etherethanolamine $(2: 1, v / v)$. Samples $(3 \mathrm{ml}$.) were counted in a Packard Tri-Carb model 314EX scintillation counter, the counting solution consisting of toluene-ethylene glycol monomethyl ether $(2: 1, v / v)$ containing $5 \cdot 5 \mathrm{~g}$. of 2-phenyloxazole/l. (Jeffey \& Alvarez, 1961) (efficiency 43\%).

Radioactivity of urine. The urine was diluted approximately $1: 1(v / v)$ with ethanol and centrifuged to remove any precipitate, which was subsequently found to contain no radioactivity. A sample of the supernatant was counted in the scintillation counter by using a counting solution consisting of $1500 \mathrm{ml}$. of dioxan, $150 \mathrm{~g}$. of naphthalene, $7 \mathrm{~g}$. of 2-phenyloxazole and $300 \mathrm{mg}$. of 1,4-bis-(5-phenyloxazole-2-yl)benzene (efficiency $45 \%$ ).

Radioactivity of faeces. The faeces were stored at $-17^{\circ}$ and immediately before combustion were freeze-dried, pulverized and weighed. Duplicate samples (30-80 mg.) were weighed into combustion bags, and binder $(0.2 \mathrm{ml}$. of $10 \%$ sucrose) was added (Kelly, Peets, Gorden \& Buyske, 1961). The samples were dried again and burnt in $\mathrm{O}_{2}$. The $\mathrm{CO}_{2}$ was collected in $15 \mathrm{ml}$. of trapping solution and $3 \mathrm{ml}$. samples were counted as described above.

\section{RESULTS}

Partitioning of the ${ }^{14} \mathrm{C}$ label among the respiratory carbon dioxide, urine and faeces. Carbon dioxide, urine and faeces samples were collected and measured until it was evident that no more radioactive material was being excreted or until 8 days had passed, whichever occurred first. The average recovery of the dose in each of these fractions is given in Tables 1 and 2. For the retinoic acid experiments almost all of the original radioactivity was recovered within 2-3 days, whereas for those with retinyl acetate a much longer time was needed. The excretion of radioactivity from the $\left[{ }^{14} \mathrm{C}\right]$ retinyl acetates continued in an almost linear fashion during the 8-day experimental period (Fig. 2). For convenience, the ${ }^{14} \mathrm{CO}_{2}$ excretion was followed for only 2 days in most experiments. To estimate the degree of participation of each of the three excretory routes of ${ }^{14} \mathrm{C}$ derived from retinyl acetate and to compare it with the retinoic acid data, the radioactivity excreted in the faeces, the urine and the carbon dioxide in the 2-day period was calculated as a percentage of the total amount excreted in that period. It is to be expected that a lag must exist between the time of formation of the faecal products and their appearance in the faeces. This lag appeared to be 1 day for the retinyl acetate experiments, since little radioactivity was detected in the faeces during the first

\section{Table 1. Recovery of ${ }^{14} \mathrm{C}$ from rats given radioactive retinoic acid}

The values are given as means \pm S.D., where S.D. was based on values obtained from individual rats. The numbers in parentheses indicate the numbers of rats. The dose of labelled retinoic acid was $14 \cdot 5 \mu \mathrm{g}$. in each case.

Recovery of ${ }^{14} \mathrm{C}$ (\% of dose)

$\begin{array}{lccc} & {\left[6,7.14 \mathrm{C}_{2}\right] \text { Retinoic acid }} & {[14-14 \mathrm{C}] \text { Retinoic acid }} & {[15-14 \mathrm{C}] \text { Retinoic acid }} \\ \mathrm{CO}_{2} & 0 \cdot 8 \pm 0 \cdot 4(2) & 18 \cdot 9 \pm 3 \cdot 4(3) & 35 \cdot 0 \pm 4 \cdot 5(2) \\ \text { Urine } & 38 \cdot 0 \pm 4 \cdot 4(4) & 18 \cdot 3 \pm 0 \cdot 3(3) & 19 \cdot 9 \pm 1 \cdot 7(5) \\ \text { Faeces } & 64 \cdot 5 \pm 1 \cdot 3(4) & 61(3)^{*} & 43 \cdot 7 \pm 3 \cdot 0(4) \\ \text { Total } & 103 \cdot 3 & 98 \cdot 2 & 98 \cdot 6\end{array}$

\footnotetext{
* The values obtained were all low owing to bacterial decomposition of the radioactive products in the faeces. However, a plot of the three values obtained (38.3, 46.6 and 52.9\%) versus the time lapse from the completion of the experiment to the time of combustion of the samples (41, 27 and 15 days) was linear and extrapolated to a value of $61 \%$ recovery of the dose at zero time.
} 


\section{Table 2. Recovery of ${ }^{14} \mathrm{C}$ from rats given radioactive retinyl acetate}

The values are given as means \pm S.D. The numbers in parentheses indicate the numbers of rats. The values for urine and $\mathrm{CO}_{2}$ represent the radioactivity recovered after 2 days; the values for faeces represent 3 days' collection to allow for the time lag in elimination. For the $1.46 \mu \mathrm{g}$. dose of [15-14C]retinyl acetate, $\mathrm{CO}_{2}$ collection was continued for 4 days, and 4 and 5 days respectively have been used for the analysis.

$\left[6,7-14 \mathrm{C}_{2}\right]$ Retinyl acetate

$\begin{array}{lcc}\text { Fraction } & \overbrace{\begin{array}{c}\text { Recovery } \\ (\% \text { of dose })\end{array}}^{(2 \cdot 0 \mu \mathrm{g} .)} & \begin{array}{c}\% \text { of } \\ \text { recovered }{ }^{14} \mathrm{C}\end{array} \\ \mathrm{CO}_{2} & 1 \cdot 5(2) & 4 \cdot 1 \\ \text { Urine } & 17 \cdot 0 \pm 2 \cdot 3(4) & 47 \cdot 2 \pm 6 \cdot 4 \\ \text { Faeces } & 17.5 \pm 2 \cdot 5(4) & 48 \cdot 7 \pm 7 \cdot 0 \\ \text { Tota } & 36 \cdot 0 & 100 \cdot 0\end{array}$

[15-14C]Retinyl acetate

\begin{tabular}{|c|c|c|c|}
\hline \multicolumn{2}{|c|}{$(2 \cdot 0 \mu \mathrm{g})}$. & \multicolumn{2}{|c|}{ (1.46 $\mu \mathrm{g})}$. \\
\hline $\begin{array}{l}\text { Recovery } \\
\text { (\% of dose) }\end{array}$ & $\begin{array}{c}\% \text { of } \\
\text { recovered }{ }^{14} \mathrm{C}\end{array}$ & $\begin{array}{l}\text { Recovery } \\
\text { (\% of dose) }\end{array}$ & $\begin{array}{c}\% \text { of } \\
\text { recovered }{ }^{14} \mathrm{C}\end{array}$ \\
\hline $\begin{array}{r}9 \cdot 9 \pm 1 \cdot 4(2) \\
9 \cdot 7 \pm 1 \cdot 9(2) \\
14 \cdot 1 \pm 1 \cdot 6(2)\end{array}$ & $\begin{array}{l}29 \cdot 4 \pm 4 \cdot 2 \\
28 \cdot 8 \pm 5 \cdot 6 \\
41 \cdot 8 \pm 4 \cdot 7\end{array}$ & $\begin{array}{c}8 \cdot 8(2) \\
8 \cdot 3 \pm 0 \cdot 8(2) \\
10 \cdot 3 \pm 2 \cdot 5(2)\end{array}$ & $\begin{array}{c}32 \cdot 1 \\
30 \cdot 3 \pm 2 \cdot 9 \\
37 \cdot 6 \pm 9 \cdot 1\end{array}$ \\
\hline 33.7 & $100 \cdot 0$ & $27 \cdot 4$ & $100 \cdot 0$ \\
\hline
\end{tabular}

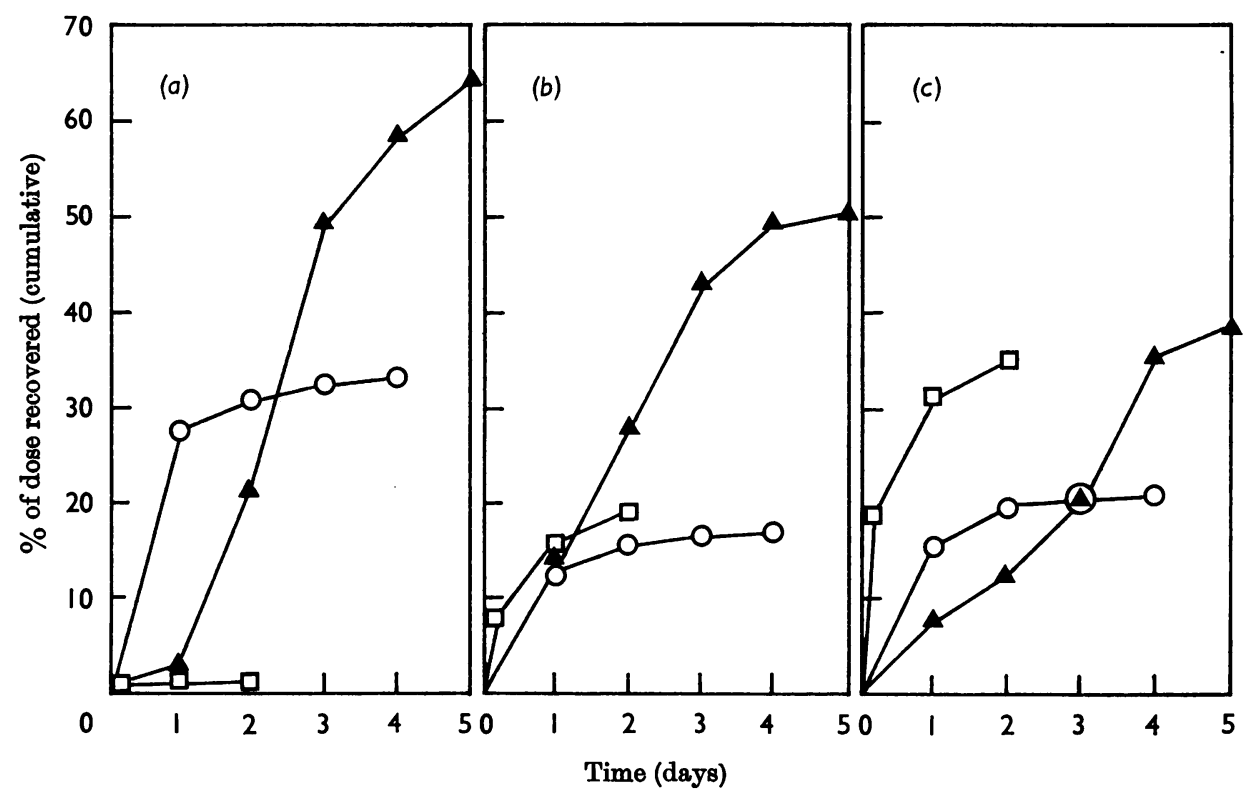

Fig. 1. Metabolism of a 14.5 $\mu \mathrm{g}$. dose of $\left[6,7-14 \mathrm{C}_{2}\right]$ retinoic acid $(a),[14-14 \mathrm{C}]$ retinoic acid $(b)$ or $[15-14 \mathrm{C}] \mathrm{retinoic}$ acid (c). The recovery of ${ }^{14} \mathrm{C}$ is shown as partitioned between the urine $(O)$, the respiratory $\mathrm{CO}_{2}(\square)$ and the faeces $(\Delta)$. Each experimental point represents the average for two rats.

24hr. of the experiment. For this reason the radioactivity found in the faeces 3 days after injection of the retinyl acetate was considered to be a measure of the radioactive products formed in the 2 days after the injection.

The data in Table 1 reveal several aspects of the metabolism of retinoic acid. Almost none of the $6,7-{ }^{14} \mathrm{C}_{2}$ label appeared in the carbon dioxide, but it was found in an approximately $3: 2$ ratio in the faecal and urinary fractions respectively. With the ${ }^{14-14} \mathrm{C}$ - or ${ }^{15}-14 \mathrm{C}$-labelled compounds, on the other hand, a considerable portion of the radioactivity was recovered in carbon dioxide. With retinyl acetate, again the $6,7 \cdot{ }^{14} \mathrm{C}_{2}$ label appeared in the urinary and faecal fractions and not in the carbon dioxide. However, the ${ }^{15-14} \mathrm{C}$ label was recovered in carbon dioxide, urine and faeces in approximately equal amounts.

Rate of retinoic acid and retinyl acetate metabolism. Radioactive retinoic acid was metabolized quite rapidly (Fig. 1). The rate was greatest in the period up to $5 \mathrm{hr}$. after injection of the dose. After 2 days, 


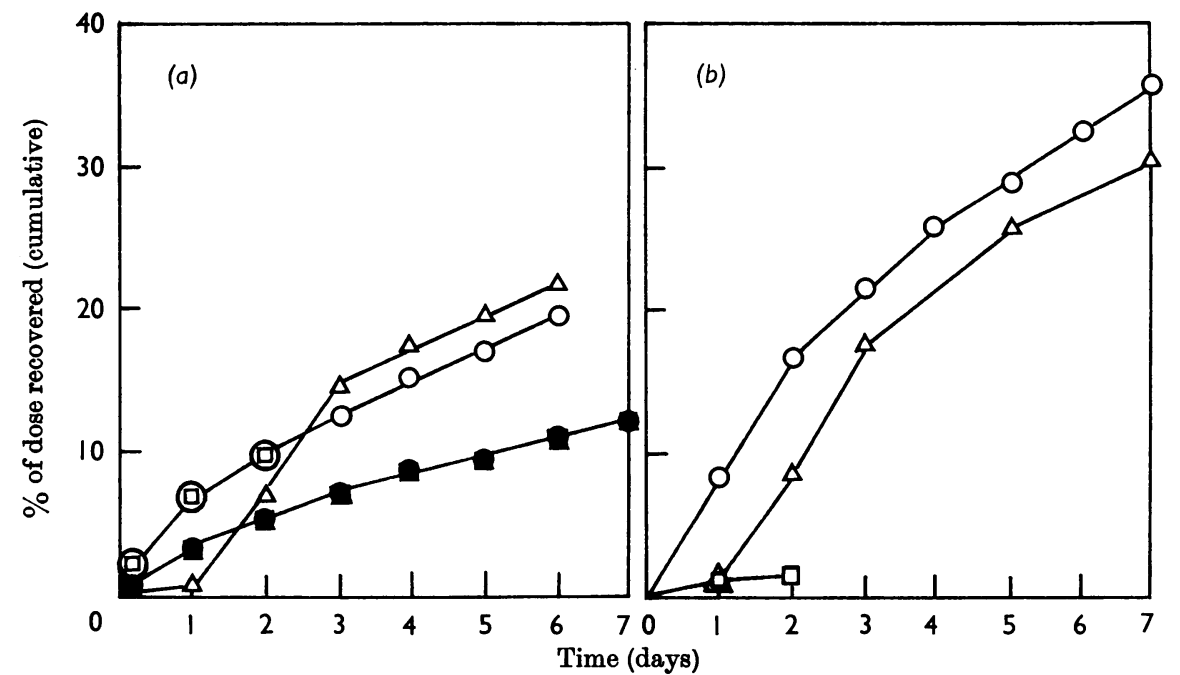

Fig. 2. Metabolism of $\left[15-{ }^{14} \mathrm{C}\right]$ retinyl acetate $(a)$ or $\left[6,7-14 \mathrm{C}_{2}\right]$ retinyl acetate $(b)$ in retinol-deficient rats. The black symbols $(\bullet, \square, \Delta)$ represent a dose of $1.46 \mu \mathrm{g}$., the others $(O, \square, \Delta)$ represent a dose of $2 \cdot 0 \mu \mathrm{g}$. The recovery of ${ }^{14} \mathrm{C}$ is shown as partitioned between the urine $(O, \odot)$, the respiratory $\mathrm{CO}_{2}(\square, \square)$ and the faeces $(\Delta, \Delta)$. (The

- $\square$ and $\Delta$ symbols are superimposed.) Each experimental point represents an average for two to four rats.

almost all of the dose had been recovered in the three excretory fractions, taking into account the lag in elimination of the faeces. Retinyl acetate, however, was metabolized at a much lower but almost constant rate (Fig. 2). The rate of retinyl acetate metabolism by retinol-deficient rats was dependent on the dose (Fig. 2). However, the partitioning of that amount metabolized between urine, carbon dioxide and faeces remained unchanged (Table 2). Radioactivity from the labelled retinyl acetate continued to be excreted after 8 days, when measurement of the samples was discontinued.

\section{DISCUSSION}

The availability of radioactive retinyl acetate and retinoic acid labelled with ${ }^{14} \mathrm{C}$ in different positions made it possible to study the breakdown of these compounds and the excretory routes of the products after metabolism by retinol-deficient rats. The amounts of the compounds used in these experiments approached the minimum daily dose necessary for maximum growth (Zile \& DeLuca, 1965). It was hoped that this procedure would minimize the degradation of the labelled compounds by other pathways that might be unrelated to the growth-supporting function.

On the basis of the present results outlines of at least three pathways for the metabolism of retinoic acid and retinyl acetate can be postulated (Scheme 1). These pathways were developed from the retinoic acid data, but it was found that they could be applied to the retinyl acetate data as well. The extent of the participation of each pathway for both retinyl acetate and retinoic acid is given in Table 3. In deriving these pathways, the basic assumption was that radioactivity appearing in the faeces and urine from $\left[15-{ }^{14} \mathrm{C}\right]$ retinoic acid resulted from an intact isoprenoid chain; therefore such a product should also contain an equivalent amount of radioactivity from C-6, C-7 and C-14. On this basis, the percentage of the dose accounted for by the radioactivity from $15-14 \mathrm{C}$-labelled compounds in the urine and faeces was designated pathway I.

Since more [15-14C]- than [14-14C]-retinoic acid was metabolized to ${ }^{14} \mathrm{CO}_{2}$, some metabolism involved decarboxylation of the terminal carbon atom of the side chain. If the rest of the side chain were left intact, the product should still be $14-{ }^{14} \mathrm{C}$ and $6,7-14 \mathrm{C}_{2}$-labelled. Because the percentage of the dose appearing in the urine from [15-14 $\mathrm{C}$ retinoic acid was approximately equal to that from the corresponding $14-{ }^{14} \mathrm{C}$-labelled compound, the product of such a pathway would appear to be excreted in the faeces. Thus pathway II was postulated to involve a decarboxylation of C-15 to yield a product, retaining C-6, C-7 and C-14, which is excreted in the faeces. In agreement with this postulate, the radioactivity in the carbon dioxide from $\left[15^{14} \mathrm{C}\right]$ retinoic acid minus that from the 14-14 C-labelled compound equals the faecal $14^{-14} \mathrm{C}$ label minus the faecal $15-14 \mathrm{C}$ label, and the faecal 


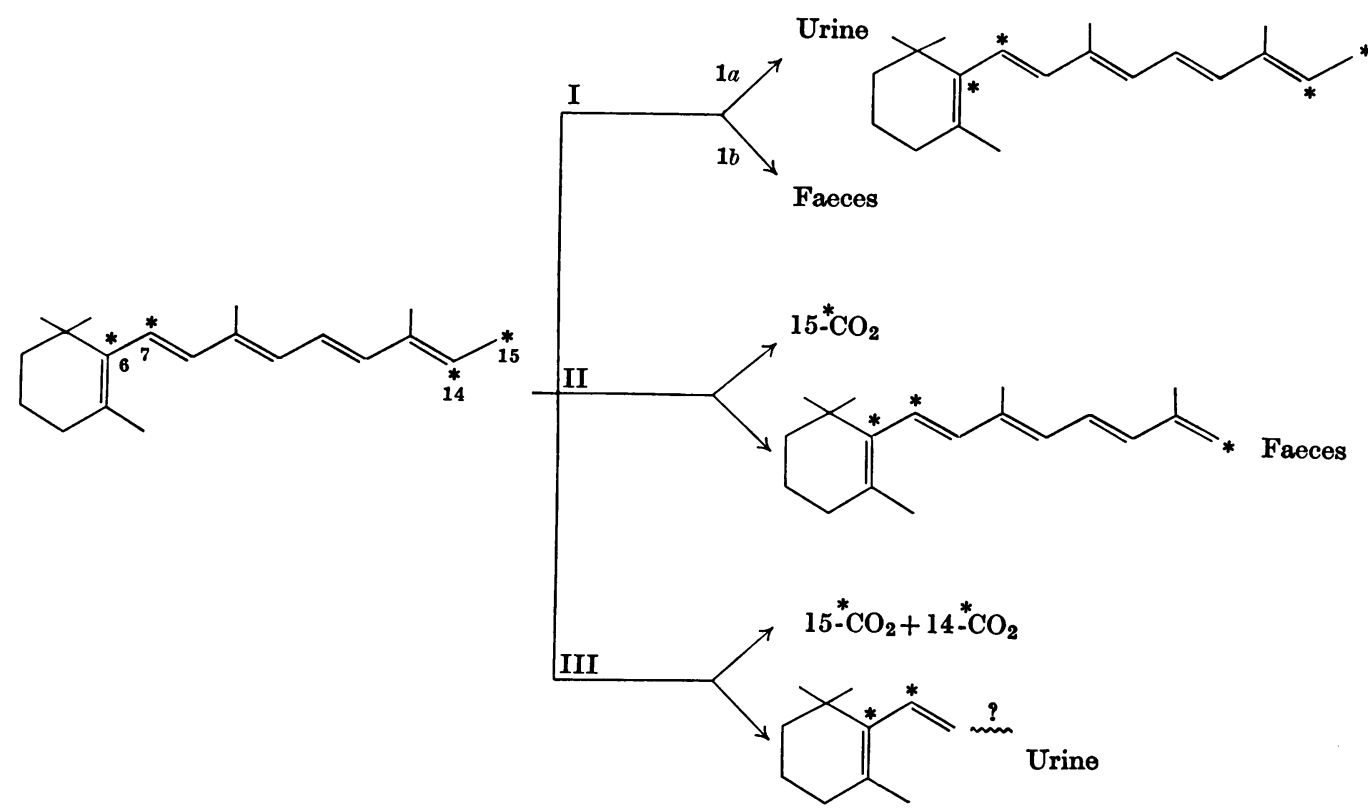

Scheme 1. Possible metabolic pathways for retinoic acid or retinyl acetate: $*$ indicates the position of the ${ }^{14} \mathrm{C}$ label. The structures shown represent the portion of the retinoic acid or retinol molecule that would become incorporated into a product after metabolism by the suggested pathways.

Table 3. Estimates of percentages of retinoic acid or retinyl acetate metabolized by the postulated pathways at low dosage levels

Pathways $1 a$ and $1 b$ are subdivisions of pathway I, and represent the distribution of the presumed intact side chain in the urinary and faecal products respectively.

\begin{tabular}{|c|c|c|}
\hline Pathway & $\begin{array}{c}\text { Retinoic acid } \\
(\%)\end{array}$ & $\begin{array}{c}\text { Retinyl acetate } \\
(\%)\end{array}$ \\
\hline I & $62-65$ & $67-79$ \\
\hline $1 a$ & $(18-20)$ & $(30-32)$ \\
\hline $1 b$ & $(43-45)$ & $(36-38)$ \\
\hline II & $18-20$ & $9-12$ \\
\hline III & $18-20$ & $17-19$ \\
\hline
\end{tabular}

$6,7 \cdot{ }^{14} \mathrm{C}_{2}$ label is approximately equal to the faecal 14-14C label.

Finally, a pathway that accounts for the elimination of ${ }^{14} \mathrm{CO}_{2}$ from both $\left[15-{ }^{14} \mathrm{C}\right]$ - and $\left[14^{-14} \mathrm{C}\right]$ retinoic acid may be postulated. The products of such a pathway must retain the $6,7 \cdot{ }^{14} \mathrm{C}_{2}$ label, since it is evident that oxidative degradation of the side chain to carbon dioxide does not proceed as far as these positions. Only in the urine is there a greater percentage of the radioactivity from $\left[6,7-{ }^{14} \mathrm{C}_{2}\right]$ - than from $\left[14-{ }^{14} \mathrm{C}\right]$-retinoic acid. By subtracting the percentage of the $14^{-14} \mathrm{C}$ label in the urine from the percentage of the $6,7-{ }^{14} \mathrm{C}_{2}$ label in the urine, a measure of this pathway is obtained. As might be expected, it is approximately equal to the percentage of the ${ }^{14}-{ }^{14} \mathrm{C}$ label found as ${ }^{14} \mathrm{CO}_{2}$. Without more data, it cannot be said whether the elimination of C-14 as carbon dioxide operates in sequence with terminal decarboxylation, or whether C-14 and C-15 are cleaved as part of a $\mathrm{C}_{2}$ or larger fragment that is then metabolized to carbon dioxide. In the foregoing discussion the data for the metabolism of retinoic acid have been treated in the simplest possible fashion: the actual metabolic processes are probably more complex.

The calculations discussed above can be represented by the following formulae:

Pathway $\mathrm{I}=15 .{ }^{14} \mathrm{C}$ in urine (pathway $1 a$ ) and $15 .{ }^{14} \mathrm{C}$ in faeces (pathway $1 b$ )

Pathway $\mathrm{II}=15^{-14} \mathrm{C}$ in $\mathrm{CO}_{2}-14^{-14} \mathrm{C}$ in $\mathrm{CO}_{2}$ $=14^{-14} \mathrm{C}$ in faeces $-15-^{14} \mathrm{C}$ in faeces

Pathway III $=14^{-14} \mathrm{C}$ in $\mathrm{CO}_{2}=6,7 \cdot{ }^{14} \mathrm{C}_{2}$ in urine $-15-14 \mathrm{C}$ in urine

Other relationships:

$6,7-14 \mathrm{C}_{2}$ in faeces $=14^{-14} \mathrm{C}$ in faeces $15 \cdot{ }^{14} \mathrm{C}$ in urine $=14^{-14} \mathrm{C}$ in urine

Here, for example, the designation ' $15-14 \mathrm{C}$ in urine' refers to that amount of radioactivity (expressed as percentage of dose) recovered in the urine after administration of $\left[15^{14} \mathrm{C}\right]$ retinoic acid.

Once derived for retinoic acid, these same 
formulae were used for retinyl acetate. Here, only data on the ${ }^{15-14} \mathrm{C}$ and $6,7-14 \mathrm{C}_{2}$ labels were available, but the equalities, together with the pathway formulae, made the calculation possible without the $14-{ }^{14} \mathrm{C}$ label. The $14-{ }^{14} \mathrm{C}$ label only adds clarity to pathway III and provides support for pathways I and II. The data for both compounds can be handled by the same formulae, or in other words administration of both compounds results in a 'pathway I' type of metabolism as well as two types of oxidation, the product of one type appearing in the faeces and the other in the urine. This is evidence that the metabolism of the two compounds proceeds along similar or identical routes.

Most significant in comparing the metabolism of these two compounds is that about one-third of the administered dose of either retinoic acid or the retinyl acetate is terminally decarboxylated (pathways II and III). For this to occur, the terminal carbon atom of retinol must become oxidized to the carboxyl state before any loss of the carbon atom can occur. Although it might be that the oxidized retinol differs chemically or isomerically from retinoic acid, it nevertheless appears that the metabolism of the side chains might be carried out by the same enzyme systems and that retinol metabolism might proceed through retinoic acid as an intermediate. It remains to be shown, however, whether retinoic acid itself is a normal intermediate in retinol metabolism or whether it feeds into the retinol pathway at some later point.

The metabolism resulting in the retention in the urine and faeces of the radioactivity of C-6, C-7, C-14 and C-15 is of major importance, for it accounts for nearly two-thirds of the metabolism of both retinoic acid and retinyl ester. It has been assumed that this metabolism leaves the isoprenoid side chain intact, for the alternative possibility, that each of the three labelled positions could be on different fragments of the molecule, seems remote. The excretion of the products of such a pathway in the urine and faeces varies somewhat between retinoic acid and retinyl acetate; this might arise from the great difference in their rate of metabolism. The greater extent of incorporation into faecal products found for retinoic acid might be related to the large initial concentration of retinoic acid derivatives in the bile (Zachman, Dunagin \& Olson, 1966). Products with an intact isoprenoid chain might include retinoyl $\beta$-glucuronic acid, which Dunagin, Meadows \& Olson (1965) have characterized in the bile of rats treated with retinoic acid. Another possibility is that retinoic acid and retinyl acetate are eliminated unchanged or as polar conjugates.

It is apparent from these experiments that the rate of metabolism of retinyl acetate is regulated 20 and that it is much lower when smaller doses are given. The dose of retinoic acid is almost entirely metabolized within $48 \mathrm{hr}$., whereas the metabolism of retinol, even at the $1 \cdot 5 \mu \mathrm{g}$. and $2 \mu \mathrm{g}$. dosage level, proceeds at a constant rate for 5 days or longer (Figs. 1 and 2). This indicates a control mechanism at a step before the entrance of retinoic acid into the pathway. It is possible that this occurs by feedback control by retinoic acid or some other metabolite, or that it is due merely to a low turnover rate for some enzyme between retinol and retinoic acid.

We thank Hoffmann-La Roche and Co. for their generous gift of the $\left[6,7-14 \mathrm{C}_{2}\right]$ - and $[15-14 \mathrm{C}]$-retinoic acid. This work was supported by Grant GB3086 from the National Science Foundation, and A.R. received support from Grant 2T1GM $236 \mathrm{BCH}$ of the National Institutes of Health and as a Predoctoral Fellow by Public Health Service Fellowship 1F1 GM-30014-01. The work is published with the approval of the Director of the Wisconsin Agricultural Experiment Station.

\section{REFERENCES}

Arens, J. F. \& van Dorp, D. A. (1946a). Nature, Lond., $157,190$.

Arens, J. F. \& van Dorp, D. A. (1946b). Nature, Lond., $158,522$.

DeLuca, H. F., Manatt, M. R., Madsen, N. \& Olson, E. B. (1963). J. Nutr. 81, 383.

DeMan, Th. J., van Leeuwen, P. H. \& Roborgh, J. R. (1964). Nature, Lond., 201, 77.

Deshmukh, D. S., Malathi, P. \& Ganguly, J. (1965). Biochim. biophys. Acta, 107, 120.

Dmitrovskii, A. A. (1961). Biokhimiya, 26, 109.

Dowling, J. E. \& Wald, G. (1960). Proc. nat. Acad. Sci., Wash., 46, 587.

Dunagin, P. E., Meadows, E. H. \& Olson, J. A. (1965). Science, 148, 86.

Dunagin, P. E., Zachman, R. D. \& Olson, J. A. (1964). Biochim. biophys. Acta, 90, 432.

Elder, T. D. \& Topper, Y. J. (1962). Biochim. biophys. Acta, 64, 430.

Futterman, S. (1962). J. biol. Chem. 237, 677.

Futterman, S. \& Saslaw, L. D. (1961). J. biol. Chem. 236, 1652.

Jeffey, H. \& Alvarez, J. (1961). Analyt. Chem. 33, 612.

Kelly, R. G., Peets, E. A., Gorden, S. \& Buyske, D. A. (1961). Analyt. Biochem. 2, 267.

Krishnamurthy, J., Bieri, J. G. \& Andrews, E. L. (1963). J. Nutr. 79, 503.

Mahadevan, S., Murthy, S. K. \& Ganguly, J. (1962). Biochem. J. 85, 326.

Sharman, I. M. (1949). Brit. J. Nutr. 3, viii.

Wald, G. \& Hubbard, R. (1948-49). J. gen. Physiol. 32, 367.

Wright, G. J. (1960). Amer. J. clin. Nutr. 9, 26.

Zachman, R. D., Dunagin, P. E. \& Olson, J. A. (1966). J. Lipid Res. 7, 3.

Zachman, R. D. \& Olson, J. A. (1961). J. biol. Chem. 236, 2309.

Zile, M. \& DeLuca, H. F. (1965). Biochem. J. 97, 180.

Bioch. 1967, 102 